\title{
Inhibitory learning and memory in the lesser octopus (Eledone cirrhosa)
}

\author{
W. F. ANGERMEIER and KIRSTEN DASSLER \\ Marine Behavior Research Station, Lettermullen, Republic of Ireland \\ and University of Cologne, Cologne, Germany
}

\begin{abstract}
Eleven octopi (Eledone cirrhosa) were deprived of food for $24 \mathrm{~h}$ and then were presented individually a paper model of a crab, a live crab as a model, and a neutral letter $\mathrm{T}$ on the outside of the testing tank for 5, 10, and 3 days, respectively. When there was no approach to the model for 20 min, the model was removed and a live crab was introduced into the tank. The results indicated that (1) octopi are capable of inhibitory learning, (2) they can transfer the learned inhibition to a natural feeding situation, (3) they remember the learned inhibitions for at least 37 days, and (4) the number of approaches vary with the models-it is highest for the live crab model and lowest for the neutral T model.
\end{abstract}

There are many publications that attest to the behavioral capabilities of the octopus. Purely behavioral studies, however, are rare. Notable exceptions are the experiments by Papini and Bitterman (1991), Fiorito, von Planta, and Scotto (1990), Boulet (1977), Barlow and Sanders (1974), Messenger and Sanders (1972), and Crancher, King, Bennett, and Montgomery (1972). These studies demonstrated successful appetitive conditioning, discrimination learning, problem-solving ability, and free operant conditioning.

Curiously absent in this list are studies on inhibitory learning. In the experiment reported here, we tried to find an answer to the following question: Is the octopus capable of learning not to approach certain models and then able to transfer this learned inhibition to a normal feeding situation?

\section{METHOD}

\section{Subjects}

Eleven octopi of the subspecies Eledone cirrhosa were used as subjects. The animals were caught by a trawler of the Irish fishing fleet off the west central Atlantic coast of Ireland. The animals weighed between 110 and $925 \mathrm{~g}$ at the start of the experiment.

\section{Apparatus}

The apparatus consisted of the living tanks $(90 \times 30 \times 40 \mathrm{~cm}$ high), which were also used as testing tanks, and three models: a paper crab, a live crab, and a neutral paper shaped like a "T."

\section{Procedure}

After arrival in the laboratory, the animals were individually adapted to their living tanks for a period of 6-8 weeks, during which time they were on ad-lib feeding of crabs. Twenty-four hours before the experiment, the animals were deprived of food.

Thanks are extended to Captain Martin Conneely of the "Juda Naofa" and his crew for procuring the animals. Correspondence should be addressed to W. F. Angermeier, Psychologisches Institut, Universität zu Köln, Züpicher Strasse 45, 5000 Köln 41, Germany.
The experiment consisted of five phases:

1. A black paper model of a crab was placed on the outside of the tank. The experiment was terminated if the octopus did not approach the model during a $30-\mathrm{min}$ period or $20 \mathrm{~min}$ after the last approach. The model was then removed, and a live crab was introduced into the tank. This procedure was repeated for all animals once a day on 5 consecutive days.

2. The same procedure was repeated with a live crab as a model for a period of 10 days.

3. Again, the same procedure was used with a $T$ as a model for 3 more days.

4. Seven days later, the animals were tested for their memory, using a live-crab model during a single trial.

5. Thirty-seven days later, the procedure under (4) was repeated again. An approach was counted as such, if and when the octopus either extended one or more arms across the model on the outside of the tank or covered the model with its body.

The rationale for using this procedure was as follows. Crabs are the natural and preferred prey for Eledone cirrhosa. Therefore, by using a paper- or live-crab model, the prey-approach behavior of the octopus should be inhibited. By introducing a live crab into the tank immediately following the removal of the model, we were testing the transfer of the inhibition from the model to the live-feeding situation. If inhibition occurred and transferred, then the octopus should take significantly longer to catch the crab in the tank on trials where it approached the model than on trials where it did not approach the model.

\section{RESULTS AND DISCUSSION}

The median number of approaches to the three models and during Memory Tests 1 and 2 were as follows: There were 5 approaches to the paper-crab model, 10 approaches to the live-crab model, 1 approach to the $T$, and none during Memory Tests 1 and 2. These results show the differential attractiveness of the models and the memory capabilities of the octopus for inhibitory learning.

The progression of inhibition during the two important phases of the experiment were as follows: There were, on the average, 7 approaches to the paper-crab model during the first 2 days and only 2.3 approaches during the last 2 days. In the live-crab model situation, there were, on the average, 15.6 approaches during the first 5 days and only 8 approaches during the last 5 days. 
Table 1

Crab-Seizure Time

\begin{tabular}{|c|c|c|c|c|}
\hline \multirow[b]{2}{*}{ Model } & \multicolumn{2}{|c|}{$\begin{array}{c}\text { No Approaches } \\
\text { to Models }\end{array}$} & \multicolumn{2}{|c|}{$\begin{array}{c}\text { 1+ Approaches } \\
\text { to Models }\end{array}$} \\
\hline & Below $M$ & Above $M$ & Below $M$ & Above $M$ \\
\hline Paper Crab & 5 & 6 & 3 & 7 \\
\hline Live Crab & 10 & 0 & 0 & 10 \\
\hline$T$ & 6 & 4 & 4 & 2 \\
\hline
\end{tabular}

Note $-M=$ median.

Table 1 shows the most important findings of this experiment, an analysis of crab-seizure time during the first three phases of the experiment. In the paper-crab condition, 5 animals showed a crab-seizure time below the general median and 6 showed a crab-seizure time above the general median following trials in which no approach to the model was shown. Using the binomial test, the results were not significant. In the live-crab situation, 10 animals showed a crab-seizure time below the median and no animal showed a time above the median following trials in which no approach to the model took place $(p<.001)$. In the T-model condition, 6 animals were below the median and 4 above it in trials in which no approach was evident ( $p$ was not significant).

For the trials in which 1 or more approaches took place, the results were analogous to the ones above (paper-crab model, 7 animals above the median crab-seizure time and 3 below, $p$ was not significant; live-crab model, 10 above median and 0 below, $p<.001 ; \mathrm{T}$ model, 2 above and 4 below, $p$ was not significant).

These findings indicate that Eledone cirrhosa is capable of transferring the learned inhibition from the livecrab model to the feeding situation in the tank, and the live-crab model shows the strongest inhibitory properties.

Next, we analyzed the qualitative aspects of learned inhibition, which we observed and quantified.

Pattern A is approach-avoidance behavior. Typically, the octopus swims or walks toward the model, stops, and returns to its original position. Pattern B consists of swimming or walking over the model, without any attempt to touch it or to land on it. Pattern C is displacement activity, which might, for example, consist of sitting in a corner

Table 2

Behavior Patterns Indicating Inhibition

\begin{tabular}{cccc}
\hline \multirow{2}{*}{$\begin{array}{c}\text { Pattern } \\
\text { Type }\end{array}$} & \multicolumn{3}{c}{ Model } \\
\cline { 2 - 4 } & Paper Crab & Live Crab & T \\
\hline A & 1.95 & 3.74 & 1.70 \\
B & 1.70 & 2.86 & 1.33 \\
C & 0.25 & 0.97 & 0.28 \\
D & 0.85 & 1.17 & 1.86 \\
\hline
\end{tabular}

Note-rho $=.87$ between the number of approaches to the live-crab model and the number of behavior patterns $(\mathrm{A}, \mathrm{B}, \mathrm{C})$ shown $(p=.01)$. and squirting water in rapid succession. Pattern D denotes sitting quietly, all curled up, in a corner of the tank.

Table 2 shows the quantitative distribution of the four behavior patterns during the three major phases of the experiment. Data are means for all trials, corrected for days. The correlation (rho) between the number of $A$ and $B$ behavior patterns (the primary patterns that indicate inhibition) and the number of approaches to the live-crab model was $.87(p<.01)$.

These results indicate that, with regard to crab-seizure time, the findings are supported by other behavior patterns, indicating inhibitory learning primarily, but not exclusively, on the live-crab model.

\section{CONCLUSIONS}

The results of this experiment lead us to the following conclusions:

1. The lesser octopus (Eledone cirrhosa) has the ability to learn inhibitory behavior patterns when presented with a model, and it can transfer this behavior to a natural feeding situation.

2. This capability is also deposited in long-term memory.

3. Different models exert different inhibitory properties; the live-crab model does so the most and the T models does so the least.

4. The fact that this capability is present in an invertebrate animal that first appeared on the evolutionary scene some 325 to 450 million years ago, attests to the importance of inhibitory learning as a regulatory mechanism in evolution. Perhaps it is now time to pay more attention to the mechanisms of inhibitory learning throughout phylogeny and the role that a model can play in such a process. The octopus seems to be an excellent animal to start with, although the human aspects of such behavior are in no way less interesting and important.

\section{REFERENCES}

Barlow, J. J., \&ANders, G. D. (1974). Intertrial interval and passive avoidance learning in Octopus vulgaris. Animal Learning \& Behavior, 2, 86-88.

BOULET, P. C. (1977). Vision and behavior among the cephalopoda. Journal de Psychologie Normale et Pathologique, 74, 91-106.

Crancher, P., King, M. G., Bennett, A., \& Montgomery, R. B. (1972). Conditioning of a free operant in Octopus cyaneus Gray. Journal of the Experimental Analysis of Behavior, 17, 359-362.

Fiorito, G., von Planta, C., a Scotto, P. (1990). Problem solving ability of Octopus vulgaris Lamarck. Behavioral \& Neural Biology, 53, 217-230.

Messenger, J. B., SAnders, G. D. (1972). Visual preference and two-cue discrimination learning in octopus. Animal Behavior, 20, 580-585.

Papini, M. R., \& Bitterman, M. E. (1991). Appetitive conditioning in Octopus cyanea. Journal of Comparative Psychology, 105, 107-114.

(Manuscript received February 24, 1992.) 